\title{
ARTICLES
}

\section{CELLULOSE DERIVATIVES BY ETHERS}

Mr. Dugga Aneel Kumar

Ph. D Scholar, Himalayan University, Arunachal Pradesh, India. DOI: http://doi.org/10.47211/tg.2020.v07i03.009

\section{ABSTRACT}

Powdered cellulose etherified to primary, secondary, tertiary, and combination of primary and tertiary carbons contains halide or an epoxide compound obtains Methylcellulose, hydroxyethyl cellulose, hydroxypropyl cellulose, and hydroxypropyl methylcellulose (OH group replaced to OR) in presence of an alkali metal hydroxide in high pressure and thermal conditions, also produced to different grades where you played a viscosity parameter.

Key Words: cellulose, alkali cellulose, etherfication.

\section{ABOUT AUTHOR}

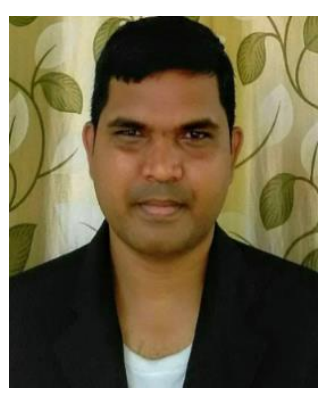

Author Mr. Dugga Aneel Kumar is a Ph. D. Scholar in Himalayan University, Arunachal Pradesh, India. 


\section{INTRODUCTION:}

Cellulose is the most abundant polysaccharide found in nature. It is a linear polymer consisting of 6-member ether rings (D-glucose or dextrose) linked together covalently by ether groups, the so-called glycosidic bonds. Usually many thousand glucose repeat units make up a cellulose polymer. Cellulose and its derivatives can be considered condensation polymers because their hydrolysis yields glucose

The cyclic structure in the main polymer chain together with strong hydrogen bonding gives cellulose a rigid structure. Thus, cellulose and some of its derivatives have a high glass transition temperature and melting point. The strong intermolecular hydrogen bonds between the hydroxyl groups lead to highly ordered crystalline regions with low accessibility to reactants which explains why cellulose is water insoluble and why strong alkalis like caustic soda are required to break down the structure to make the hydroxyl groups accessible to reactants.

Cellulose is the most abundant organic polymer on the planet. It is an important structural component of the primary cell wall of plants. The cellulose content of cotton fibres is about 90 percent. Not surprising, it is the main raw material for many semi-synthetic cellulose der Cellulose is the most abundant polysaccharide found in nature. It is a linear polymer consisting of 6-member ether rings (D-glucose or dextrose) linked together covalently by ether groups, the so-called glycosidic bonds. Usually many thousand glucose repeat units make up a cellulose polymer. Cellulose and its derivatives can be considered condensation polymers because their hydrolysis yields glucose molecules:

The cyclic structure in the main polymer chain together with strong hydrogen bonding gives cellulose a rigid structure. Thus, cellulose and some of its derivatives have a high glass transition temperature and melting point. The strong intermolecular hydrogen bonds between the hydroxyl groups lead to highly ordered crystalline regions with low accessibility to reactants which explains why cellulose is water insoluble and why strong alkalis like caustic soda are required to break down the structure to make the hydroxyl groups accessible to reactants.

Cellulose is the most abundant organic polymer on the planet. It is an important structural component of the primary cell wall of plants. The cellulose content of cotton fibres is about 90 present. Not surprising, it is the main raw material for many semi-synthetic cellulose derivatives.

Manly cellulose contains $\beta$ and $\alpha$ cellulose, alpha-cellulose has crystalline and beta-cellulose has low molecular weight like starch.

Calculation formula

100- $\left(\mathrm{S}_{10}+\mathrm{S}_{18}\right) / 2$

Where- $\mathrm{S}_{10}=$ Solubility of $10 \% \mathrm{NaOH}$ solution.

$\mathrm{S}_{18}=$ Solubility of $18 \% \mathrm{NaOH}$ solution.

Degradation only alpha-cellulose, so $\mathrm{S}_{10}$ value is disabled.

Figure-1

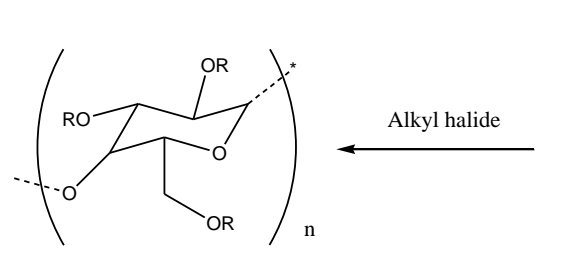

$\mathrm{R}=\mathrm{H}$ or $\mathrm{CH} 3$ Methyl cellulose

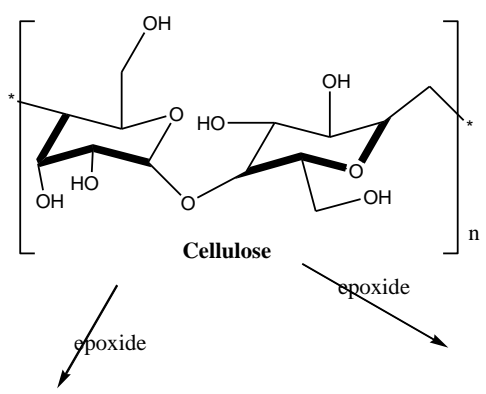

Alkyl halide, epoxide n
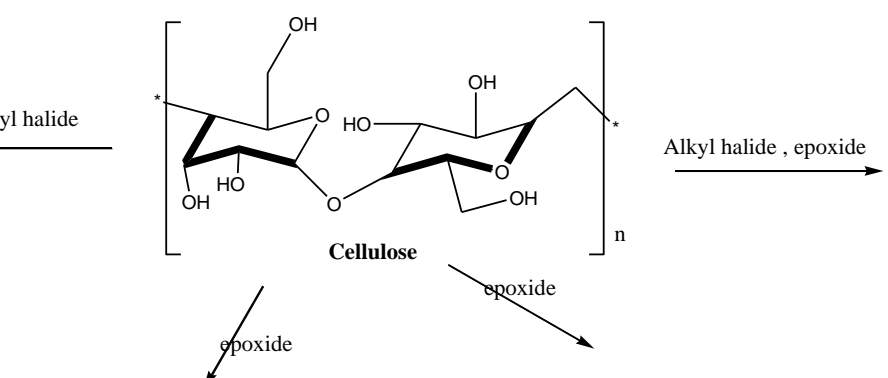

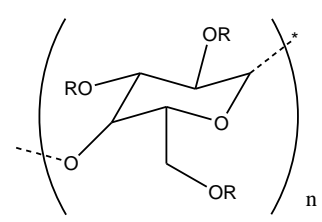

$\mathrm{R}=\mathrm{H}$ or $\mathrm{CH} 3$ or $\mathrm{CH} 2 \mathrm{CH}(\mathrm{OH}) \mathrm{CH} 3$ hydroxypropyl methyl cellulose

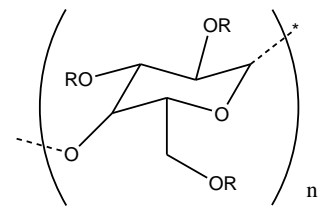

$\mathrm{R}=\mathrm{H}$ or $\mathbf{C H 2 C H 2 O H}$

hydroxyethyl cellulose

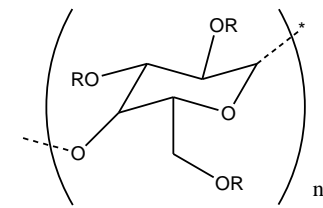

$\mathrm{R}=\mathrm{H}$ or $\mathrm{CH} 2 \mathrm{CH}(\mathrm{OH}) \mathrm{CH} 3$

hydroxypropyl cellulose 


\section{Preparation of Alkali Cellulose}

Taken 1 mole of grinded cellulose and added 10-15 times of Aqueous $\mathrm{NaOH}$ (percentage it doesn't matter means use $10-50 \%$ also) at room temperature for 1-2 hrs followed by filtration than filtrate treat with any $10-$ 15 volume of Alcohol followed by filtration and filtrate dried for $1-2$ hours at $50-70^{\circ} \mathrm{C}$ than milled and sieve for uniformity to powder form.

Or

Incentive reaction: direct take grand cellulose charged Aq. $\mathrm{NaOH}$ or Alcohol-NaOH than followed by etherification. No need for 2nd-time alcohol treatment/ above process.

\section{Etherification of Alkali cellulose}

Take the 1 mole of above-dried alkali cellulose into the pressure reactor than added to 15-20 times of Acetone for vigorous string purpose than added very slowly 5 moles of methylation reagents methyl chloride gas, methyl iodide, and dimethyl sulfoxide at RT in close pressure conditions due to methyl chloride is low boiling gas, its exothermic reaction so add very slowly to alkali cellulose than reaction maintained at $60^{\circ} \mathrm{C}$ reflux temperature for $3 \mathrm{hrs}$ then take the jelly type of methylcellulose. Don't go for incentive reaction because in presence of aqueous medium methyl chloride reacts to get bi-product $\mathrm{HCl}$ and methanol so $\mathrm{HCl}$ not forward to reaction properly, if you go for an incentive reaction take 1 mole of grinded cellulose than added to 1:10 of $10 \%$ sodium methoxide in alcohol (methanol)/acetone than add very slowly 5 moles of methyl chloride gas at Room temperature than maintained for $3 \mathrm{hrs}$ at $70^{\circ} \mathrm{C}$ in closed conditions for Methylcellulose (MC).

Take the 1 mole of cellulose than added to $0.5 \mathrm{~mol}$ of $\mathrm{NaOH}$ and 10-15 volumes of Acetone or Toluene than added very slowly ethylene oxide gas at RT it's very exothermic reaction temperature shoot up like anything so reaction maintained for Room Temperature for $30 \mathrm{~min}$ than reaction maintained for $3 \mathrm{hrs}$ at $50^{\circ} \mathrm{C}$, after that obtained jelly type mass its hydroxyethyl cellulose (HEC).

Taken the 1 mole of Alkali cellulose than added 10-15 volumes of Acetone or toluene as a solvent than added 5 moles of propylene oxide than reaction $1-2 \mathrm{hrs}$ at $70-120^{\circ} \mathrm{C}$ in closed /pressure system then after maintains gummy like bubblegum mass obtained its hydroxypropyl cellulose (HPC).

HPMC preparation the same as the Methylcellulose (MC) process no changes, only introduce or extra added of very little 0.3 moles of propylene oxide into the reaction, at the same time react hydroxypropyl and methyl groups it's obtained of hydroxypropyl methylcellulose (HPMC).

\section{Work up / isolation procedure}

All cellulose derivatives are after etherification its jelly form so material unloaded as such than wash with Hot water washings through 80-150 mesh Vibro shifting filtration, material like jelly form so it's difficult to the filtration of cloth or paper, etherified cellulose not soluble in hot water, in cold water it's soluble. the excess of base removed as much as in above hot water washings so remaining unwashed $\mathrm{NaOH}$ traces neutralized with glacial acetic acid to the form of sodium acetate, $\mathrm{pH}$ adjustment is very important because in basic medium cellulose degraded means yellows colour forms may be unreacted epoxides react to $\mathrm{NaOH}$ traces the form of diols its colour impurity develops, and in the strong base in presence of water hydrolysis will be possible so neutralized with week acid if used strong acid in presence of water hydrolysis will de happen acid medium also, after $\mathrm{pH}$ adjustment salts wash with Hot water around $90^{\circ} \mathrm{C}$ temperature, followed by mesh filtration than material vacuum dried at $90^{\circ} \mathrm{C}$. mill the material suitable equipment crystalline white solids was obtained.

Substitutions values are given table-1 and the structure shown in figure-1.

\section{Colour improvement}

Cellulose colour degrades in thermal conditions in presence of basic medium, in maybe diols bi-products also make a colour issue, long time cellulose storage in the base medium also yellowish colour develops in the surface. So colour improvement to etherified cellulose $\mathrm{pH}$ neutralized when etherified cellulose in basic medium if no colour change $\mathrm{pH}$ adjustment also go for bleach with $\mathrm{H} 2 \mathrm{O} 2$, alcoholic- $\mathrm{HCl}, \mathrm{CO} 2$, Ozone $\mathrm{ClO} 2$ etc.., but $\mathrm{H} 2 \mathrm{O} 2$ is best its use to beaching $\mathrm{pH}$ adjustment viscosity reducing agent also, the process takes wet or dry material of etherified cellulose to add $4 \%$ of $30 \%$ concentration of $\mathrm{H} 2 \mathrm{O} 2$ with respect to the dry base than heated to $100-120^{\circ} \mathrm{C}$ for $30 \mathrm{~min}-1 \mathrm{hr}$ then completely remove of $\mathrm{H} 202$ by hot water washings if $\mathrm{H} 202$ percent in the material in drying time material more de-polymerized and dark black colour was obtained if ppm levels also depolymerised a long time after drying also.

\section{Viscosity increasing to etherification by cellulose}

Basically, after etherifications of cellulose increasing the viscosity more than cellulose. If further increasing to viscosity after alkylation or in reaction added alcohols as a co-solvent it protects to cellulose degradation as well as viscosity increasing agent. the co-solvent of alcohols is acted as chain transfer reagent of surface so wide chain formed in surface more molecular weight automatically more viscous material, and its act as protecting groups also so molecular weight increasing automatically more viscous, choosing of alcohol is very 
important example methylcellulose is a reagent as an alkyl halide here co-solvent is ethanol/secondary alcohols if propylation co-solvent is tertiary alcohol like terry butyl alcohol.

\section{Viscosity reduction by depolymerisation reactions}

Mainly etherified cellulose is high, medium and low viscous grades above discussed high viscous, here high viscous to medium and low viscous grade material by depolymerisation.

depolymerisation by viscosity reduction only effect of side/surface interlinked chains only it's not any effected of main or direct bonds, so assay doesn't changes, change molecular weight only, so molecular weight is low viscosity also low.

the first process if material high viscous so in above-discussed work up before $\mathrm{pH}$ adjustment only water washings material (material in excess of $\mathrm{NaOH}$ traces) heated to $100-120^{\circ} \mathrm{C}$ for $1-3 \mathrm{hrs}$ obtained medium or low viscous material, then adjust $\mathrm{pH}$ to neutralized followed by hot water washings and dry the compound for white crystalline powder.

the second one by $\mathrm{H} 2 \mathrm{O} 2$ method the process takes wet or dry material of etherified cellulose to add $4 \%$ of $30 \%$ concentration of $\mathrm{H} 2 \mathrm{O} 2$ with respect to the dry base than heated to $100-120^{\circ} \mathrm{C}$ for $30 \mathrm{~min}-1 \mathrm{hr}$ then completely remove of $\mathrm{H} 2 \mathrm{O} 2$ by hot water washings if $\mathrm{H} 2 \mathrm{O} 2$ percent in the material in drying time material more depolymerized and dark black colour was obtained, if ppm levels also depolymerised a long time after drying also.

the third one takes wet or dry material of etherified cellulose to add 5 volumes of dry Acetone-Hcl with $1-2 \%$ $\mathrm{HCl}$ content for $1-5 \mathrm{hrs}$ at $30-50^{\circ} \mathrm{C}$ (time and \% of $\mathrm{HCl}$ and temperature depend on viscosity graded ). then material filter and filtrate treat with $1-2 \%$ of $30 \%$ ammonium hydroxide in acetone followed by acetone washings by filtration than material dried white colour solid obtained. in this $\mathrm{HCl}$ reduction, better not to use wet conditions due to the presence of water/moisture main bonds will be hydrolyzed so its effect to assay values of MS and DS values, and in wet conditions filter action has problem filtration done only Vibro shifter so in the dry condition it's easy to filtration by vacuumed, and Acetone $\mathrm{HCl}$ don't store for long time its moisture pickup as well colour develops, don't go for more than $3 \% \mathrm{HCl}$ content of Acetone- $\mathrm{HCl}$ if more than $3 \%$ material rapidly hydrolysis and it's not heterogeneous material decomposed very fast its cant be isolation.

Table-1

Plant/commercial specifications' of MS and DS values of substitutions

\begin{tabular}{|l|l|l|l|l|}
\hline S.No & Name & $\begin{array}{l}\text { Methyl } \\
\text { content }\end{array}$ & Hydroxyethyl contant & $\begin{array}{l}\text { Hydroxypropyl } \\
\text { content }\end{array}$ \\
\hline 1 & Methylcellulose (MC) & $27.5-31.5 \%$ & ----- & ----- \\
\hline 2 & hydroxyethyl cellulose (HEC) & ----- & $56-68 \%$ & ----- \\
\hline 3 & hydroxypropyl cellulose(HPC) & ----- & Between 53.4 to $80.5 \%$ & ----- \\
\hline 4 & $\begin{array}{l}\text { hydroxypropyl } \\
\text { methylcellulose(HPMC) }\end{array}$ & $28-30 \%$ & ----- & $7-12 \%$ \\
\hline
\end{tabular}

\section{Critical parameters}

In these etherified reagents, alkyl halides and epoxides are low boiling point compounds and toxic so the reaction is only preferable in pressure reactors. Alkyl halide reagent reaction most probably avoided to moisture/aqueous medium in presence of water reaction, not proceed properly. if jell form difficult to due filtration Vibro shifter also material dissolved to chloro compound solvents like chloroform or dichloromethane than $\mathrm{pH}$ neutralized than extract to cold water heated to $100^{\circ} \mathrm{C}$ in hot condition material wormed out water filter and dry the compound for white crystalline powder.

Applications of cellulose derivatives by etherification

1. Bioadhesive and mucoadhesive drug delivery system.

2. Extended release solid dosage forms.

3. enteric-coated solid dosage form.

4. Compressibility enhancers.

5. Disintegrating agent.

6. Taste-masking agent.

\section{REFERENCES}

1. Brown, G., Ley, H. Science 1965, 147, 1038.

2. Chu, S., Jeffrey, G. Acta Cryst. 1968, B24, 830.

3. Hermanutz, F., Meister, F., Uerdingen, E. Chemical Fibres Int. 2006, 6, 342-344.

4. Haworth, W. N. Helv. Chim. Acta 1928, 11, 534. 


\section{ARTICLES}

5. Haworth, W. N. Ber. Dtsch. Chem. Ges. (A) 1932, 65, 43.

6. Klemm, D., Philipp, B., Heinze, T., Heinze, U., Wagenknecht, W. Comprehensive Cellulose Chemistry, Volume 1, Fundamentals and Analytical Methods, Wiley-VCH, Weinheim, 1998.

7. www.tappi.com

8. Krässig, H. Cellulose, Polymer Monographs Volume 11, Gordon and Breach Science Publishers, Amsterdam, 1996, 6-42.

9. Payen, A. 'Troisième mémoire sur le development végétaux'Extrait des mémoires de l'Academie Royale des Sciences: Tomes III des Savants Éntranges, Imprimerie Royale, Paris, 1842.

10. Staudinger, H. Die hochmolekularen organichen Verbindungen - Kautschuk und Cellulose, 2nd Ed., Springer Verlag, Berlin, 1960. 